\title{
Microstructural and chemical characterization of hydroxylapatite obtained from sandollar and monetite by electron microscopy
}

\author{
V. Rodríguez-Lugo*, C. Angeles-Chavez ${ }^{* *}$ \\ *Instituto de Física Benemérita Universidad Autónoma de Puebla Apartado Postal J48 Puebla \\ 72570, México. \\ ** Instituto Mexicano del Petroleo, Programa de Investigacion y Desarrollo de Ductos, Eje Central \\ Lazaro Cardenas 152, 07730 México D.F.
}

The hydroxylapatite crystals are considered as biomaterials due to the high biocompatibility with the osseous tissue [1]. Currently it is being a very important necessity, to obtain hydroxylapatite crystals to low cost. The sand dollar (mellita eduardobarrosoi sp. Nov.) is a rich source of calcium carbonate and can be used as a low cost precursor.

Scanning electron microscopy (SEM) and transmission electron microscopy (TEM) are important tools to characterize this material type because we can investigate their morphological, chemical and structural characteristic to determine the specific application.

In this work, hydroxylapatite was synthesized through a hydrothermal process using a stoichiometric ration of sand dollar [2] and monetite as precursors in a reaction time of 2, 4, 6, 8, 10 and $20 \mathrm{hr}$. At $20 \mathrm{hr}$ was determined as better reaction time $[3,4]$. Als o, the synthesis was explored with different $\mathrm{CaO}$ concentration. Hydroxylapatite, whitocklite, portlandite and monetite were the main crystalline phases identified. The morphological characteristics in the samples were observed by SEM. Figure 1a shows a typical morphology observed in the stoichiometric sample sustained during $20 \mathrm{hr}$ of reaction. The crystals are observed as fibbers which correspond to the hydroxylapatite phase. Figure $1 \mathrm{~b}$ illustrates the morphology obtained with the lowest $\mathrm{CaO}$ concentration. In this case, small particles were observed as agglomerated . Other morphology types were observed in the samples with an excess $\mathrm{CaO}$. TEM was used to identify the morphology, crystalline structure and chemical composition of the single hydroxylapatite crystals. These are illustrated in figure 2 . The hydroxylapatite crystals found, they had a shape of fibber (figure 2a). Electron diffraction patterns obtained from these morphologies showed some forbidden reflections (Figure 2b). Small amount of $\mathrm{Si}$ and $\mathrm{Mg}$ were detected in the chemical analysis of the crystals (figure 2c). Simulation study was carried out to explore the forbidden reflection and it found that $\mathrm{Si}$ and $\mathrm{Mg}$ play a important roll in the hydroxylapatite structure.

Authors are indebted to Maria Eufemia Fernandez and Gilberto Mondragon for her support in theoretical calculations. Also we are indebted to CONACYT for grants within the project 32605-U.

1. Lemons J. E.; General characteristics and classifications of implant material, in perspectives on biomaterials, Materials Science Monographs No. 33 (O. C. Lin \& E. Y. S. cho. Eds.) Elsevier, Amsterdam, 1986.

2. V. Rodriguez.Lugo, G.A. Camacho-Bragado, V.M. Castaño-Meneses, Materials and Manufacturing Process, 18, 1, (2003), 67-78.

3. V. Rodríguez-Lugo, J. A. Ascencio, C. Angeles-Chavez, A. Camacho-Bragado and V.M. Castaño, Materials and Technology, 16, (2001), 97-103.

4. Ascencio-Gutierrez J., V. Rodríguez-Lugo, C. Angeles, T. Santamaría and V. M. Castaño, Computational Materials Science 25 (2002), 413-426 


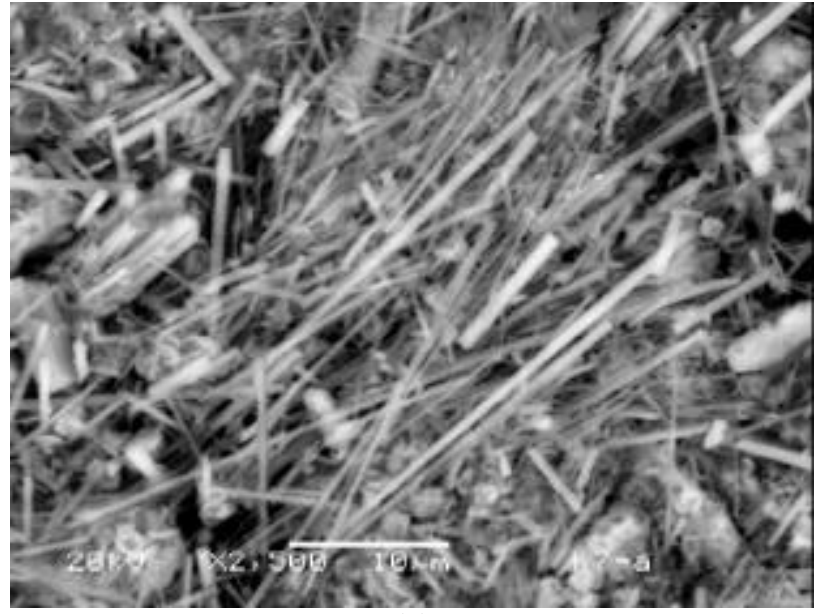

(a)

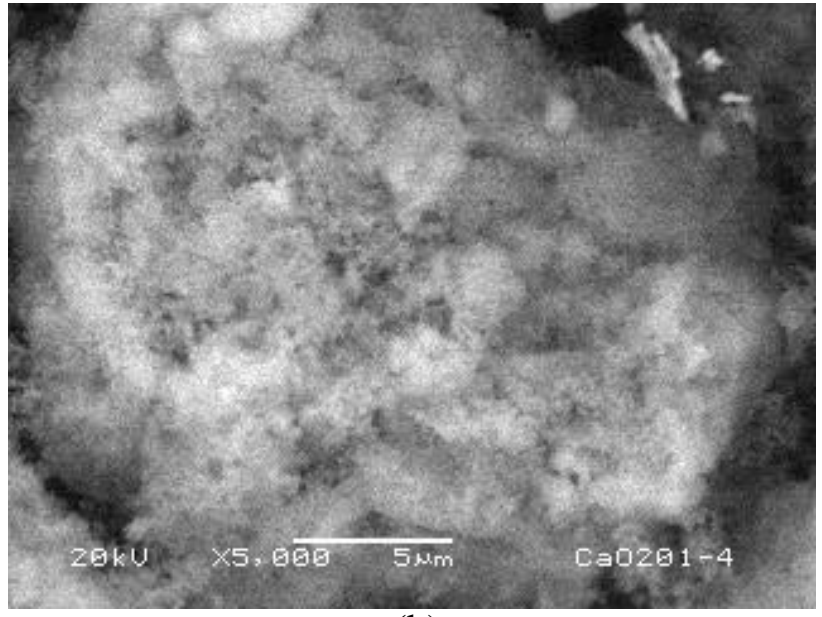

(b)

Figure 2. SEM image showing typical morphology observed a)stoichiometric ratio during $20 \mathrm{hr}$ of reaction and b)sample corresponding to the lowest $\mathrm{CaO}$ concentration.

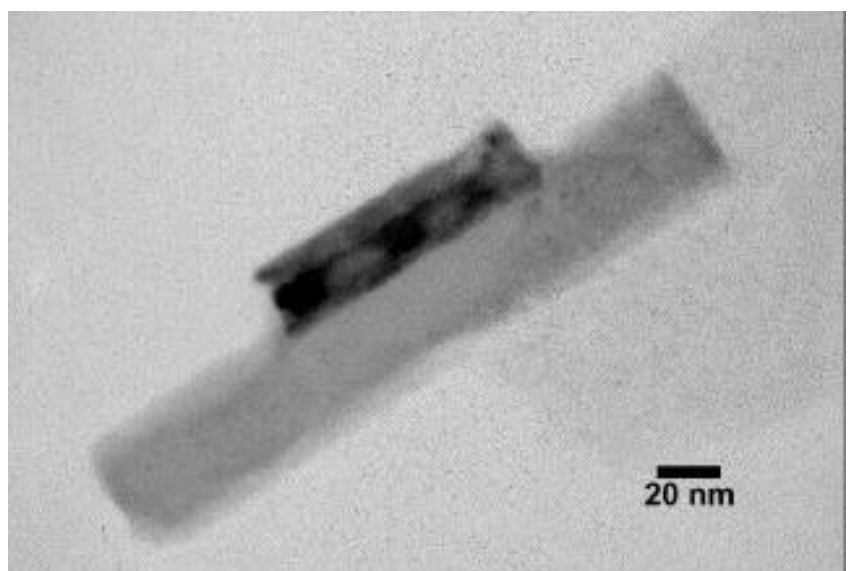

(a)

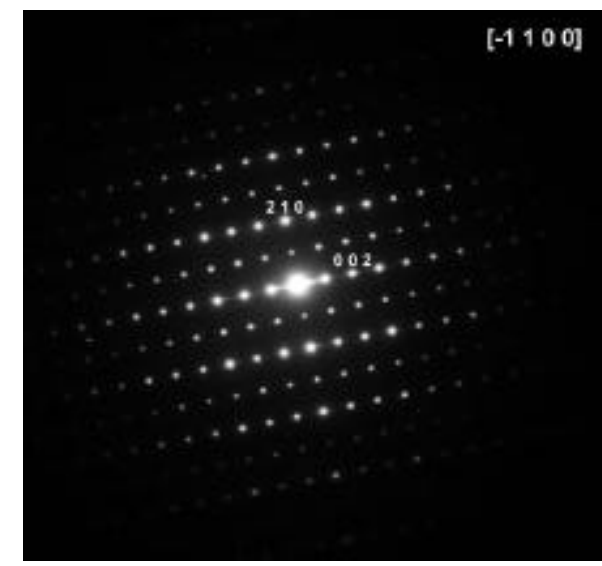

(b)

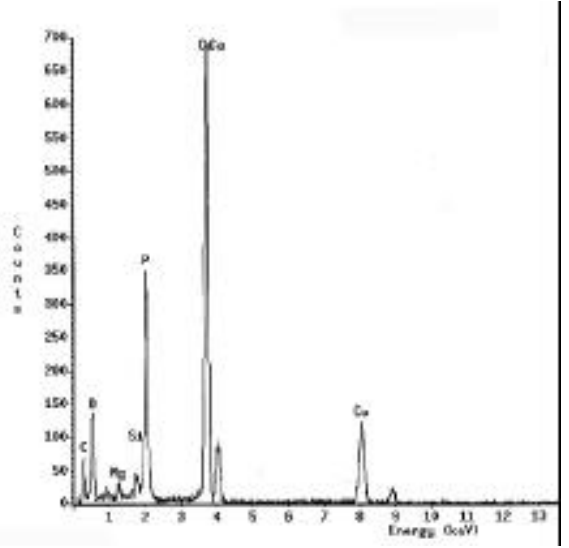

(c)

Figure 2. TEM image illustrating a)typical morphology of the hydroxylapatite crystals b)electron diffraction pattern obtained from this morphology and c)typical chemical composition of the hydroxylapatite crystals. 